\title{
Occurrence of Antibiotic Residues and Antibiotic-Resistant Bacteria in Nile Tilapia Sold in Accra, Ghana: Public Health Implications
}

\author{
Eric S. Donkor ${ }^{1}$, Isaac Anim-Baidoo ${ }^{2}$, Evans $\mathrm{Fei}^{2}$, Collins Amponsah ${ }^{2}$, Michael Olu-Taiwo ${ }^{2}$, David Nana-Adjei ${ }^{2}$, \\ Enid Owusu ${ }^{2} \&$ Akua Obeng Forson ${ }^{2}$ \\ ${ }^{1}$ Dept. of Medical Microbiology, School of Biomedical and Allied Health Sciences, University of Ghana, Ghana \\ ${ }^{2}$ Dept. of Medical Laboratory Science, School of Biomedical and Allied Health Sciences, University of Ghana, \\ Ghana \\ Correspondence: Akua Obeng Forson, Dept. of Medical Laboratory Science, School of Biomedical and Allied \\ Health Sciences, University of Ghana, Ghana. Tel: 233-541-937-023. E-mail: obeng.akua@yahoo.com
}

Received: May 10, 2017

Accepted: May 31, 2017 Online Published: November 20, 2018

doi:10.5539/jfr.v7n6p129

URL: https://doi.org/10.5539/jfr.v7n6p129

\begin{abstract}
In Ghana there are concerns that antibiotics may be used inappropriately to boost fish production, though no study has investigated this problem. To provide preliminary insights into public health aspects of the problem, we investigated the occurrence of antibiotic residues and antibiotic-resistant bacteria in Nile tilapia (Oreochromis niloticus), a fish commonly cultivated and consumed in Ghana. Two hundred Nile Tilapia fish were randomly sampled from four major markets in Accra, the capital city of Ghana. One hundred samples were screened for antibiotic residues using a microbial inhibition plate test that detects sixteen different antibiotics commonly used in animal husbandry and aquaculture. The other 100 samples were cultured for bacteria using direct culture methods, and the isolates were tested against seven antibiotics by the Kirby Bauer method. The overall prevalence of antibiotic residues in the fish samples was 7\%. Bacteria that were isolated from the fish samples were Shigella sonnei (10\%), Enterobacter cloacae (7\%), Escherichia coli (6\%), Salmonella Typhi (3\%), Klebsiella pneumoniae (2\%), and Proteus mirabilis (2\%). All bacteria isolated were susceptible to gentamicin and ciprofloxacin but resistant to ampicillin. Multi-drug resistance (ie resistance to three or more different classes of antibiotics) occurred in $86.7 \%$ of the isolates. Nile Tilapia sold in Accra is a source of multi-drug resistant bacteria. Consumption of the fish can also lead to significant exposure to antibiotic residues.
\end{abstract}

Keywords: antibiotic residues, multi-drug resistance, fish, Shigella sonnei

\section{Introduction}

Antibiotics are used in aquaculture for several reasons including treatment and prevention of fish diseases, increment in fish reproduction and tranquilization such as in weighing (Cabello, 2006; Kim et al., 2011). Common antibiotics used in aquaculture include tetracyclines, penicillins, chloramphenicol, fluoroquinolones, sulfonamides and macrolides (Cabello, 2006; Kim et al., 2011; Samanidou \& Evaggelopoulou, 2007). The dependency on antibiotics in aquaculture can have negative effects on the health of humans, as well as damage to the environment (Kim et al., 2011; Buschmann et al., 2006; Sorum, 2006). Certain antibiotics in fish products, particularly penicillin can evoke allergic reactions even if small amounts are ingested; it is known that about $10 \%$ and $3.4 \%$ of humans have allergic sensitivity to penicillin and sulphonamide respectively (Wassenaar, 2005; Sundlof, 2004). Chloramphenicol can cause aplastic anaemia, while broad-spectrum antibiotics such as metronidazole may adversely affect a wide range of intestinal flora and consequently cause gastrointestinal disturbance (Wassenaar, 2005; Sundlof, 2004). To protect public health against toxicological risk of antibiotics used in animal husbandry and aquaculture, maximum residue limits have been established for various antibiotics as well as acceptable daily intakes (FAO, 2005; JECFA, 2005). Additionally, withdrawal periods have been defined for these antibiotics to prevent animal source food contamination.

The widespread use of antibiotics in aquaculture has resulted in the emergence of antibiotic-resistant bacteria in aquaculture environments. In Australia, a study on fish and fish ponds showed widespread resistance among Pseudomonas aeruginosa and Pseudomonas fluorescens (Ndi \& Barton, 2012). L'Abée-Lund \& Sørum (2001) have reported the presence of tetracycline resistance associated with tet (A) and tet (E) resistance genes in tranposons and integrons in multi-resistant Aeromonas salmonicida isolated from fishes from Finland, France, 
Japan, Norway, Scotland, Switzerland, and the United States. In Turkey, a study showed varying levels of multi-resistance in some gram-negative bacteria from wastewater river containing fishes (Toroglu \& Korkmaz, 2005). A study in Nigeria with Salmonella Enteritidis recovered from fishes revealed varying levels of resistance (Raufu et al., 2014).

Commercial aquaculture now exists in a huge scale in many developed and developing countries. In Ghana, the aquaculture industry is relatively young and faced with significant challenges involving production intensification and disease control (ATFALCO, 2012). In order to address some of these issues, antibiotics are sometimes used in fish cultivation. Currently, there are concerns that antibiotics may be used inappropriately in aquaculture in Ghana, though there has been no study to investigate the problem. To provide preliminary insights into the public health aspects of the problem, we investigated the occurrence of antibiotic residues and antibiotic resistant bacteria in Nile Tilapia (Oreochromis niloticus), a fish commonly cultivated and consumed in Ghana.

\section{Methods}

\subsection{Study Area, Design and Sampling}

The study was carried out in four markets in Accra, including Agbobgloshie, Kaneshie, Makola and Weija markets from May 2014 to July 2015. Accra is the capital city of Ghana and has a population of 2.5 million people (Population and Housing Census, 2010). The four sites selected for the study are markets where residents of Accra commonly purchase fish. A wide range of fishes are sold on these markets, however only a few types including tilapia and catfish are from aquaculture sources. In Ghana, Tilapia is the major fish species cultivated and constitutes over 80 percent of aquaculture production (ATFALCO, 2012).

Two hundred fresh fish samples of Nile Tilapia (Oreochromis niloticus) were randomly sampled from the four markets. The fish samples were transported to the bacteriology laboratory of School of Biomedical and Allied Health Sciences, University of Ghana in Accra for analysis. The first 100 fish samples collected were screened for antibiotic residues while the other 100 samples were cultured for bacteria followed by antimicrobial susceptibility testing of the isolates.

\subsection{Determination of Antibiotic Residues in Fish Samples}

Fish samples were screened for antibiotic residues using the microbial inhibition method described by Koenen-Dierick et al. (1995). Briefly, 0.5 McFarland's standard suspension of Bacillus subtilis ATCC 6633 was prepared and used to inoculate the surface of Muller-Hinton agar (MHA) plates. A sterile cork borer of $3 \mathrm{~mm}$ in diameter was used to create four wells on the agar plates. Using a sterile forceps and scalpel blade, $3 \mathrm{~mm}$ of the gill of each tilapia sample was cut and transferred aseptically into the cut wells. For each MHA plate, positive and negative controls were set up with penicillin $(1 \mathrm{mg} / \mathrm{mL})$ and sterile distilled water respectively. The agar plates were incubated at $37^{\circ} \mathrm{C}$ for $18-24$ hours. After incubation, the plates were examined for zones of inhibition. Any well containing fish gills with $\geq 1 \mathrm{~mm}$ zone of inhibition was considered positive for antibiotic residue (Koenen-Dierick et al., 1995)

\subsection{Isolation and Identification of Bacteria from Fish Samples}

Sterile swab sticks were used to swab the gut regions of the fish samples and inoculated into Brain-heart infusion broth and Rappaport-Vassiliadis broth. The inoculated broths were incubated at $37^{\circ} \mathrm{C}$ for $18-24$ hours and subcultured onto MacConkey, Blood and Xylose Lysine Deoxycholate agar plates. After incubation at $37^{\circ} \mathrm{C}$ for 18-24 hours, bacterial isolates were identified based on colonial morphology, Gram stain and a battery of biochemical tests such as the triple sugar iron test, catalase test, urease test, indole test and citrate utilization test (Baron et al., 1994).

\subsection{Antimicrobial Susceptibility Testing}

Antimicrobial susceptibility testing of bacterial isolates were determined by the Kirby Bauer method (Bauer $e t$ al., 1966; CLSI, 2010). On the agar plate of the test organism, a sterile loop was used to touch four to five morphologically similar colonies and inoculate $5 \mathrm{~mL}$ sterile peptone water until the turbidity was comparable to $0.5 \%$ McFarland's standard. A loopful of the suspension was transferred to a Mueller-Hinton agar plate, and a sterile cotton swab was used to streak the entire surface of the plate. The lid of the agar plate was left ajar for 3 to 5 minutes to allow for any excess surface moisture to be absorbed before applying the drug impregnated disks. The antibiotics tested included ceftriaxone $(30 \mu \mathrm{g})$, gentamicin $(10 \mu \mathrm{g})$, cefuroxime $(30 \mu \mathrm{g})$, meropenem $(10 \mu \mathrm{g})$, amikacin $(30 \mu \mathrm{g})$, cotrimaxole $(25 \mu \mathrm{g})$ and ciprofloxacin $(5 \mu \mathrm{g})$, ampicillin $(10 \mu \mathrm{g})$, cefotaxime $(30 \mu \mathrm{g})$, chloramphenicol $(30 \mu \mathrm{g})$. The agar plates were incubated at $37^{\circ} \mathrm{C}$ for $18-24$ hours, after which zone diameters around the antibiotic discs were measured and classified as sensitive or resistant based on the CLSI break point system (CLSI, 2010). Quality control testing was done by using Escherichia coli ATCC25922 strain for 
validation of the susceptibility testing process.

\subsection{Data Analysis}

The data were analysed using STATA 11 (Strata Corp., College Station. TX, USA). Descriptive analysis including frequencies and percentages were computed for antibiotic residues and various bacterial organisms in the fish samples. The Chi-square test was used to compare these parameters among the various markets and a $p$ value $<0.05$ was considered to be significant. Analysis of frequencies and percentages were also done for resistant and multi-drug resistance isolates. Multidrug resistance was defined as resistance to three or more classes of antibiotics.

\section{Results}

\subsection{Prevalence of Antibiotic Residues in Fish Samples}

The prevalence of antibiotic residues in fish sampled from the markets is shown in Table 1. While none of the fish samples from Agbobloshie market tested positive, prevalence of antibiotic residues in samples from Kaneshie and Makola markets were $11.8 \%$ and $9.1 \%$ respectively. The overall prevalence of antibiotic residues in the fish samples was 7\%; generally, there was no significant difference in the prevalence of fish contamination among the different markets at $\mathrm{p}<0.05$.

Table 1. Prevalence of antibiotic residues in fish sampled from markets in Accra (Ghana)

\begin{tabular}{lccc}
\hline Name of Market & Number of samples tested & Number of positive samples & \% of positive samples \\
\hline Agbobloshie & 33 & 0 & 0 \\
Kaneshie & 34 & 4 & 11.8 \\
Makola & 33 & 3 & 9.1 \\
Weija & 0 & 0 & 0 \\
\hline Overall & 100 & 7 & 7 \\
\hline
\end{tabular}

No fish samples from Weija market were tested for antibiotic residues; No significant difference in positive samples from the different markets.

\subsection{Bacteria Isolated from Fish Samples}

For the 100 fish samples screened by culture, 6 different types of bacterial pathogens were isolated from 46 samples. As shown in Table 2, the most prevalent organism was Shigella sonnei (10\%), followed by Enterobacter cloacae (7\%), Escherichia coli (6\%), Salmonella Typhi (3\%) and Klebsiella pneumoniae/Proteus mirabilis (2\%).

Unlike the other study markets, fish samples from Makola market harboured all the 6 bacterial pathogens while samples from Agbobloshie market were least contaminated. Generally, there was no significant difference in the types of bacteria isolated from the different markets $(\mathrm{p}>0.05)$.

Table 2. Bacteria isolated from fish sampled in markets in Accra (Ghana)

\begin{tabular}{lccccc}
\hline Bacteria & \multicolumn{5}{c}{ Market } \\
\cline { 2 - 6 } & Agbobloshie & Kaneshie & Makola & Weija & Overall \\
\cline { 2 - 6 } & $\mathbf{n}(\%)$ & $\mathbf{n}(\%)$ & $\mathbf{n}(\%)$ & $\mathbf{n}(\%)$ & $\mathbf{n}(\%)$ \\
\hline Shigella sonnei & $0(0)$ & $5(20)$ & $4(16)$ & $1(4)$ & $10(10)$ \\
Enterobacter cloacae & $0(0)$ & $4(16)$ & $2(8)$ & $1(4)$ & $7(7)$ \\
Escherichia coli & $1(4)$ & $0(0)$ & $2(8)$ & $3(12)$ & $6(6)$ \\
Salmonella Typhi & $0(0)$ & $0(0)$ & $1(4)$ & $2(8)$ & $3(3)$ \\
Klebsiella pneumoniae & $0(0)$ & $1(4)$ & $1(4)$ & $0(0)$ & $2(2)$ \\
Proteus mirabilis & $0(0)$ & $0(0)$ & $2(8)$ & $0(0)$ & $2(2)$ \\
\hline
\end{tabular}

$n$ indicates number of samples that tested positive for bacteria

$\%$ indicates corresponding percentage of positive samples

\subsection{Antibiotic Resistance of Bacteria Isolated from Fish Samples}

All the 30 isolates from fish samples were susceptible to gentamicin and ciprofloxacin but resistant to ampicillin. Prevalence of multi-drug resistance among the 30 isolates was $86.7 \%$. Multi-drug resistance occurred among all the different bacterial pathogens (Table 3). In many cases, resistance profiles of the multi-drug resistant isolates 
were highly varied within the same species (Table 4). Further analysis on the prevalence of resistance to various antibiotics was done for only Shigella sonnei as isolates of the other bacterial pathogens were insufficient for analysis. For $S$. sonnei, antibiotic resistance was observed for eight of the ten drugs tested, increasing across chloramphenicol/ceftriaxone/cefuroxime (25\%), amikacin (33\%), cefotaxime (42\%), meropenem (67\%), cotrimoxazole (83\%) and ampicillin (100\%) (Figure 1).

Table 3. Prevalence of multi-drug resistance among bacteria isolated from fish samples

\begin{tabular}{lcc}
\hline Bacteria & Number of isolates & Number of Multi-drug resistant isolates (\%) \\
\hline Enterobacter cloacae & 7 & $4(57.1)$ \\
Escherichia coli & 6 & $6(100)$ \\
Klebsiella pneumoniae & 2 & $2(100)$ \\
Proteus mirabilis & 2 & $1(50)$ \\
Salmonella Typhi & 3 & $3(100)$ \\
Shigella sonnei & 10 & $10(100)$ \\
\hline
\end{tabular}

\section{Discussion}

This study is probably the first to report on contamination of antibiotic residues in fish in Ghana. By comparison, studies on fish in Nigeria and Vietnam reported antibiotic residue contamination of $61.3 \%$ (Olatoye \& Basiru, 2013) and 29.4\% (Pham et al., 2015) respectively. In Ghana, prevalence of antibiotic residues has been reported in several animal foods including beef (30.8\%), chevon (29.3\%), pork (28.6\%), mutton (24\%), and egg (6.8\%) (Donkor et al., 2011). Generally, in the developed world, antibiotic residue contamination of animal source food is low, and in Europe prevalence rates of $<1 \%$ are generally reported (Commission of the European Communities, 2005). The relatively lower prevalence of antibiotic residues in food in the developed world can be attributed to quality assurance programmes such as educational programmes, widespread testing of food for antimicrobial drugs, and financial penalties (Commission of the European Communities, 2005; Mckenzie \& Hathway 2006). The aquaculture industry in Ghana is still young and the concept of using antibiotics in cultivation may not be widespread among farmers yet, which may explain the relatively lower prevalence of antibiotic residues in fish in this study.

Table 4. Resistance profile of multi-drug resistant bacteria isolated from fish

\begin{tabular}{lcl}
\hline Isolates & Number of isolates & Resistance pattern \\
\hline Enterobacter cloacae & 2 & TET-COT-MEM-AMP \\
\hline Escherichia coli & 2 & CTR-MEM-AMP \\
& 4 & TET-CRX-CTX-MEM-AM \\
\hline Klebsiella pneumoniae & 1 & CRX-MEM-AMP \\
& 1 & CRX-CTX-MEM-AMP \\
\hline Proteus mirabilis & 1 & TET-COT-CTX-CTR-AMP \\
\hline Salmonella Typhi & 1 & TET-COT-CTX-CTR-MEM-AMP \\
& 1 & TET-COT-MEM-AMP \\
\hline Shigella sonnei & 1 & TET-COT-CRX-CTX-MEM-AMP \\
& 1 & CRXT-CTX-MEM-AMP \\
& 2 & COT-CRX-MEM-AMP \\
& 3 & COT-COT-CRX-CTX-MEM-AMP \\
& 1 & TET-AMK-AMP-AMP \\
& 1 & TET-COT-CRX-CHL-MEM-AMP \\
& 1 & TET-CRX-CTX-MEM-AM \\
& 1 & TET-COT-CHL-CTX-MEM-AMP \\
\hline
\end{tabular}

$T E T=$ tetracycline COT= cotrimoxazole $G E N=$ gentamicin $C R X=$ cefuroxime $C H L=$ chloramphenicol $C T X=$ cefotaxime $C T R=$ ceftriaxone $M E M=$ meropenem $A M K=$ amikacin $C I P=$ ciprofloxacin $A M P=$ ampicillin 


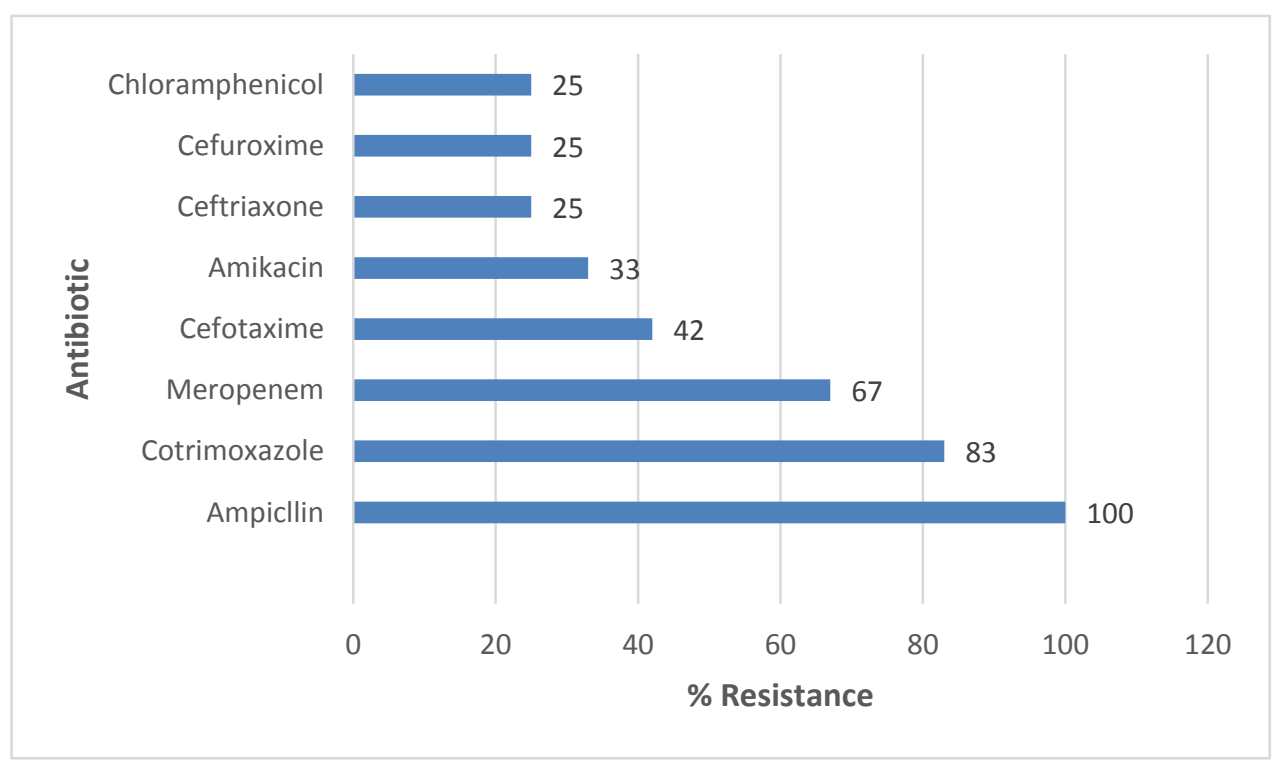

Figure 1. Percentage resistance of Shigella sonnei to various antibiotics

The microbial inhibition plate test used to screen fish for antibiotic residues in this study has a low sensitivity for macrolides but has a high sensitivity for several other antibiotics that are known to be used in animal husbandry in Ghana, such as b-lactams, tetracyclines, aminoglycosides, sulphonamides, and quinolones (Koenen-Dierick, et al., 1995; Sekyere, 2014). Overall, the test used can detect sixteen different antibiotics commonly used in animal husbandry and aquaculture. With such a wide coverage of antibiotics, we expect that our screening captured to a large extent any antibiotics used in aquaculture in Ghana. Though the test used detects a wide range of antibiotic residues in food above maximum residue limits, it is unable to differentiate the residues. Assays that detect specific antibiotics in animal food are rather expensive and include chemical methods such as chromatography and mass spectrometry (Samanidou \& Evaggelopoulou, 2007).

An overall tilapia contamination of $7 \%$ with antibiotic residues in this study translates into an average risk of exposure every fifteenth time a consumer takes in the commodity. The risk of exposure of a human population to food contaminated with antibiotic residues depends mainly on the extent of food contamination and the consumption rate of the food (Lu \& Sam, 2002; MacNeil, 2005). In this study, because we did not quantify specific drugs in the fish samples and evaluate consumption trends of the commodity, it is difficult to measure the actual risk of specific drugs to consumers. Consumption rate of tilapia in Ghana is known to be very high and some of the samples, which tested positive for antibiotic residues in this study, had large zones sizes (>31 mm) reflecting high concentration of antibiotic residues. These observations along with a fish contamination rate of $7 \%$ reflect a potentially high risk of exposure to antibiotic residues in Tilapia, though further studies are needed to throw more light on this. In Ghana, there are no national limits for antibiotic residues in fish currently. With the increasing public health concerns of antibiotic residues in fish sold in the country, it is about time for legislative establishment of such limits.

The various bacteria reported in this study have been previously isolated from fish (Onyango et al., 2009; Marcel et al., 2013, Plumb, 1999). All the organisms isolated are enteric, suggesting that faecal pollution may have played a role in the microbial contamination of the fish samples (Ashbolt et al., 2015). Consumption of fish contaminated by some of these organisms particularly, Shigella sonnei and Salmonella Typhi could pose serious threat to public health. Shigella causes shigellosis or bacillary dysentery and is specific host-adapted to humans (Shears, 1996). It has a low infectious dose and some of its outbreaks have been linked to fish consumption (Shears, 1996). Recent epidemiological evidence indicates that $S$. sonnei, which has historically been more commonly isolated in developed countries, is undergoing an unprecedented expansion across industrializing regions (Thompson et al., 2015). Consequently, it is interesting to note that S. sonnei was the predominant Shigella spp. isolated in this study, though it was previously reported to be relatively uncommon in Ghana compared to several other Shigella spp. (Opintan \& Newman, 2007). Further studies are needed to evaluate the public health significance of $S$. sonnei in Ghana in light of its changing epidemiology. $S$. Typhi causes typhoid fever, an infection, which is endemic in some parts of Ghana (Marks et al., 2010)]. Though $S$. Typhi has been isolated from several types of food in Ghana, the current study is probably the first report on fish. Generally, Salmonella is responsible 
for a huge public health problem associated with fish and fishery products and its presence in food reflects poor standard of hygiene (Heinitz et al., 2000). In light of this study, the recent efforts to expand aquaculture in Ghana could be associated with an increased risk of typhoid fever unless precautions are taken to protect public health.

Though fish samples from Agbogbloshie market were least contaminated by bacteria and were also free of antibiotic residues, it is difficult to attribute these observations to better food safety and hygienic practices at this market. This is because fish samples on the different markets originated from farm sources and may have moved through various channels before reaching the markets. For example, cross-contamination of food with microbes commonly occurs during food transportation (Stier, 2004), while drug residue contamination of food is mainly a farm level issue (Aning et al., 2007).

The extent of antibiotic resistance observed among bacteria isolated from fish is high and similar to what has been reported for clinical isolates in Ghana especially for tetracycline, chloramphenicol, ampicillin and cotrimoxazole (Opintan \& Newman, 2007; Newman et al., 2011; Labi et al., 2014). These antibiotics have been on the market in Ghana for a long time and have been subjected to a high rate of usage leading to emergence and spread of resistant strains at a high level (Donkor et al., 2012; Donkor et al., 2011; Tetteh-Quarcoo et al., 2013). Of concern is the extremely high prevalence of multi-drug resistance in pathogens of public health significance such as Shigella sonnei and Salmonella Typhi. This could have serious public health implications, especially in developing countries like Ghana where antibiotic treatment options are limited. Multi-drug resistance in enteric bacteria is mediated by mobile genetic elements such as plasmids and transposons that carry resistant genes (von Wintersdorff, et al., 2016; AbdelRahim et al., 2015; Codjoe \& Donkor, 2017). Several lines of evidence indicate that such genetic elements can be transferred from indigenous microbial flora of fish to human pathogens (Marshall \& Levy, 2011; Sorum, 2006; Akinbowale et al., 2006). It is important to note the high susceptibility of enteric bacteria to ciprofloxacin and gentamicin in this study, despite the high levels of resistance to several antibiotics in this study. This could be because these antibiotics are hardly used in aquaculture in Ghana. There is the need to limit the use of these drugs in Ghana through their prudent usage. The design of this study did not permit us to collect data on antibiotic use in aquaculture and thus it is difficult to relate this to the pattern of resistance observed. There is the need for studies to understand the epidemiology of antibiotic use in aquaculture in Ghana, as this will be an important step in solving the huge problem of antibiotic resistance in the acquaculture environment that has been exposed by this study.

There are a few limitations of the study. Firstly, the method used to screen fish samples for antibiotic residues could not identify and quantify specific antibiotics. Secondly, since the study was done at the market level, we do not have information on the origin of the fish samples. Additionally, we did not collect data on certain biological parameters of the fish samples such as sex, weight and length.

In conclusion, Nile Tilapia sold in Accra is a source of multi-drug resistant bacteria and consumption of the fish could also lead to significant exposure to antibiotic residues. Though fish is normally consumed in the cooked state thus decreasing the potential of infection, they may play a role in spreading multi-drug resistant bacteria to other food sources in the environment. The study has revealed a potentially serious public health problem. There is the need to create awareness about this among policy makers and also test for drug residues at fish distribution centres. There is also the need to include the acquaculture environment in antibiotic-resistance management and surveillance programmes in Ghana.

\section{Acknowledgments}

Laboratory assistance provided by technical staff of the Department of Medical Laboratory Sciences, School of Biomedical and Allied Health Sciences, University of Ghana is gratefully acknowledged.

\section{References}

AbdelRahim, K. A., Hassanein, A. M., \& Abd El Azeiz, H. A. (2015). Prevalence, plasmids and antibiotic resistance correlation of enteric bacteria in different drinking water resources in sohag, Egypt. Jundishapur Journal of Microbiology, 8(1), e18648.

Akinbowale, O. L., Peng, H., \& Barton, M. D. (2006). Antimicrobial resistance in bacteria isolated from aquaculture sources in Australia. Journal of Applied Microbiology, 100, 1103-1113. https://doi.org/10.1111/j.1365-2672.2006.02812.x

Aning, K. G., Donkor, E. S., Omore, A., Nurah, G. K., Osafo, E. L. K., \& Staal, S. (2007). Risk of exposure to marketed milk with antimicrobial drug residues in Ghana. The Open Food Science Journal, 1, 1-5. https://doi.org/10.2174/1874256400701010001

Ashbolt, N. J. (2015). Microbial contamination of drinking water and human health from community water 
systems. Current Environmental Health Reports, 2, 95-106. https://doi.org/10.1007/s40572-014-0037-5

ATFALCO (2012). The Ministerial Conference on Fisheries Cooperation among African States Bordering the Atlantic Ocean, Fishery and aquaculture industry in Ghana. Available from http://www.comhafat.org/fr/files/publications/112102014102624AM.pdf,

Baron, J. E., Peterson, L. R., \& Finegold, S. M. (1994). Bailey and Scott Diagnostic Microbiology. $9^{\text {th }}$ ed. Maryland Heights, MO: C V Mosby Co.

Bauer, A. W., Kikrby, W. M., Sherris, J. C., \& Turck, M. (1966). Antibiotic susceptibility testing by a standardized single disk method. American Journal of Clinical Pathology, 45(4), 493-496. https://doi.org/10.1093/ajcp/45.4_ts.493

Buschmann, A. H., Riquelme, V. A., Hernandez Gonzalez, M. C., Varela, D., Jimenez, J. E., Henriquez, L. A., Vergara, P. A., Guínez, R., \& Filun, L. (2006). A review of the impacts of salmonid farming on marine coastal ecosystems in the southeast Pacific. ICES Journal of Marine Science, 63. 1338-1345. https://doi.org/10.1016/j.icesjms.2006.04.021

Cabello, F. C. (2006). Heavy use of prophylactic antibiotics in aquaculture: a growing problem for human and animal health and for the environment. Environmental Microbiology, 8(7), 1137-1144. https://doi.org/10.1111/j.1462-2920.2006.01054.x

Codjoe, F. S., \& Donkor, E. S. (2017). Carbapenem resistance: a review. Medical Sciences, 6 (1), pii, E1.

Clinical Laboratory Standard Institute (CLSI) (2010). Performance Standards for Antimicrobial Susceptibility Testing: Eighteenth Informational Supplement Wayne: Clinical and Laboratory Standards Institute.

Commission of the European Communities (2005). Commission Staff Working Paper On The Implementation Of National Residue Monitoring Plans In The Member States In 2003 (Council Directive 96/23/Ec), Retrieved from http://www.uni-mannheim.de/edz/pdf/sek/2005/sek-2005-0025-en.pdf

Donkor, E. S., Newman, M. J., \& Yeboah-Manu, D. (2012). Epidemiological aspects of non-human antibiotic usage and resistance: implications for the control of antibiotic resistance in Ghana. Tropical Medicine and International Health, 17(4), 462-468. https://doi.org/10.1111/j.1365-3156.2012.02955.x

Donkor, E. S., Newman, M. J., Tay, S. C. K., Dayie, N. T. K. D., Bannerman, E., \& Olu-Taiwo, M. (2011) Investigation into the risk of exposure to antibiotic residues contaminating meat and egg in Ghana. Food Control, 22, 869-873. https://doi.org/10.1016/j.foodcont.2010.11.014

FAO (Food and Agriculture Organization of the United Nations), (2002). The State of World Fisheries and Aquaculture - 2002 (SOFIA). Retrieved from http://www.fao.org/docrep/005/y7300e/y7300e06.htm,

Heinitz, M. L., Ruble, R. D., Wagner, D. E., \& Tatini, S. R. (2000). Incidence of Salmonella in fish and seafood. Journal of Food Protection, 63(5), 579-592. https://doi.org/10.4315/0362-028X-63.5.579

JECFA (2005). Joint FAO/WHO Expert Committee on Food Additives. Dietary exposure assessment of chemicals in food, Annapolis, Maryland, USA. Retrieved from http://apps.who.int/iris/bitstream/10665/44027/1/9789241597470_eng.pdf

Kim, K. R., Owens, G., Kwon, S. I., So, K. H., Lee, D. B., \& Ok, Y. S. (2011). Occurrence and environmental fate of veterinary antibiotics in the terrestrial environment. Water Air Soil Pollution, 214, 163-174. http://dx.doi.org/10.1007/s11270-010-0412-2.

Koenen-Dierick, L., Okerman, L., De Zutter, L., Degroodt, J. M., Hoof, J. V., \& Srebrnik, S. A. (1995). One-plate microbiological screening testing in kidney tissue and meat; an alternative to the EEC four plate method?. Food Additives \& Contaminants, 12(1), 77-82. https://doi.org/10.1080/02652039509374281

L'Abée-Lund, M. T., \& Sørum, H. (2001). Class 1 Integrons Mediate Antibiotic Resistance in the Fish Pathogen Aeromonas salmonicida Worldwide. Microbial Drug Resistance, 7(3), 263-272. https://doi.org/10.1089/10766290152652819

Labi, A. K., Obeng-Nkrumah, N., Addison, N., \& Donkor, E. S. (2014). Salmonella blood stream infections in a tertiary care setting in Ghana. BMC Infectious Diseases, 21(14), 3857. https://doi.org/10.1186/s12879-014-0697-7

Lu, F. C., \& Sam, K. (2002). Lu's basic toxicology: fundamentals, target organs and risk assessment. Taylor \& Francis, 364. https://doi.org/10.1201/9781420055986

MacNeil, J. D. (2005). The Joint food and Agriculture Organization of the United Nations/World health 
Organization Expert Committee on food additives and its role in the Evaluation of the safety of veterinary drug residues in foods. The American Association of Pharmaceutical Scientist Journal, 7(2), E274-E280. https://doi.org/10.1208/aapsj070228

Marcel, G., Sabri, M. Y., Siti-Zahrah, A., \& Emikpe, B. O. (2013). Water condition and identification of potential pathogenic bacteria from red tilapia reared in cage-cultured system in two different water bodies in Malaysia. African Journal of Microbiology Research, 7(47), 5330-5337. https://doi.org/10.5897/AJMR12.1468

Marks, F., Adu-Sarkodie, Y., Hünger, F., Sarpong, N., Ekuban, S., Agyekum, A., Nkrumah, B., Schwarz, N. G., Favorov, M. O., Meyer, C. G., \& May, J. (2010). Typhoid fever among children, Ghana. Emerging Infectious Diseases journal, 16(11), 1796-1797. https://doi.org/10.3201/eid1611.100388

Marshall, B. M., \& Levy, S. B. (2011). Food animals and antimicrobials: impacts on human health. Clinical Microbiology Reviews, 24(4), 718-33. https://doi.org/10.1128/CMR.00002-11

Mckenzie, A. I., \& Hathway, S. C. (2006). The role and functionality of veterinary services in food safety throughout the food chain. Scientific and Technical Review of the Office International des Epizooties (Paris), 25(2), 837-848. https://doi.org/10.20506/rst.25.2.1697

Ndi, L. O., \& Barton, M. D. (2012). Resistance determinants of Pseudomonas species from aquaculture in Australia. Journal of Aquaculture Research and Development, 3, 1-6. https://doi.org/10.4172/2155-9546.1000119

Newman, M. J., Frimpong, E., Donkor, E. S., Opintan, J. A, \& Asamoah-Adu, A. (2011). Resistance to antimicrobial drugs in Ghana. Infection and Drug Resistance, 4, 215-220.

Olatoye, O. I., \& Basiru, A. (2013). Antibiotic usage and oxytetracycline residues in African catfish (Clarias gariepinus in Ibadan Nigeria). World journal of fish and marine sciences, 5(3), 302-309.

Onyango, D. M., Wandili, S., Kakai, R., \& Waindi, E. N. (2009) Isolation of Salmonella and Shigella from fish harvested from the Winam Gulf of Lake Victoria, Kenya. The Journal of Infection in Developing Countries, $3(2), 99-104$.

Opintan, J., \& Newman, M. J. (2007). Distribution of serogroups and serotypes of multiple drug resistant Shigella isolates. Ghana Medical Journal, 41(1), 4-8.

Pham, D. K., Chu, J., Do, N. T., Brose, F., Degand, G., Delahaut, P., De Pauw, E., Douny, C., Van Nguyen, K., Vu, T. D., Scippo, M. L., \& Wertheim, H. F. (2015). Monitoring Antibiotic Use and Residue in Freshwater Aquaculture for Domestic Use in Vietnam. Ecohealth, 12(3), 480-489. https://doi.org/10.1007/s10393-014-1006-z

Plumb, J. A. (1999). Tilapia Bacterial Diseases. In: Health Maintenance and Principal Microbial Diseases Cultured Fishes, Plumb, J.A. (Ed.). Iowa State University Press, Ames, IA., USA. 297-305.

Population and Housing Census: Accra: Ghana Statistical Service. (2010). Retrieved from http://www.stasghana.gov.gh.

Raufu, I. A., Lawan, F. A., Bello, H. S., Musa, A. S., Ameh, J. A., \& Ambali, A. G. (2014). Occurrence and antimicrobial susceptibility profilesof Salmonella serovars from fish in Maiduguri, sub-Saharah, Nigeria. Egyptian Journal of Aquatic Research, 40, 59-63. https://doi.org/10.1016/j.ejar.2014.01.003

Samanidou, V. F., \& Evaggelopoulou, E. N. (2007). Analytical strategies to determine antibiotic residues in fish. Journal of Separation Science, 30(16), 2549-69. https://doi.org/10.1002/jssc.200700252

Sekyere, J. O. (2014). Antibiotic Types and Handling Practices in Disease Management among Pig Farms in Ashanti Region, Ghana. Journal of Veterinary Medicine, 1-8. http://dx.doi.org/10.1155/2014/531952.

Shears P. (1996). Shigella infections. Annals of Tropical Medicine \& Parasitology, 90(2), 105-114. https://doi.org/10.1080/00034983.1996.11813034

Sorum, H. (2006). Antimicrobial drug resistance in fish pathogens. In Aarestrup F. M., editor. (ed.), Antimicrobial resistance in bacteria of animal origin. ASM Press, Washington, DC. 213-238.

Stier, R. F. (2004). Say goodbye to the weakest link. Food Engineering, 76(6), 20-21.

Sundlof, S. F. (1994). Human risks associated with drug residues in animal derived food. Journal of Agromedicine, 1, 5-22. https://doi.org/10.1300/J096v01n02 02

Tetteh-Quarcoo, P. B., Donkor, E. S., Attah, S. K., Duedu, K. O., Afutu, E., Boamah, I., Olu-Taiwo, M., 
Anim-Baidoo, I., \& Ayeh-Kumi, P. F. (2013). Microbial carriage of cockroaches in a tertiary hospital in Ghana: public health implications. Environmental Health Insights, 7, 59-66.

Thompson, C. N., Duy, P. T., \& Bake, S. (2015) The Rising Dominance of Shigella sonnei: An Intercontinental Shift in the Etiology of Bacillary Dysentery. PLOS Neglected Tropical Diseases, 9(6), e0003708. https://doi.org/10.1371/journal.pntd.0003708.

Toroglu, S., \& Korkmaz, H. (2005) Antibiotic resistance in Gram negative bacteria isolated from Aksu River in (Kahramanmaras) Turkey. Annals of Microbiology, 55(3), 229-233.

von Wintersdorff, C. J., Penders, J., van Niekerk, J. M., Mills, N. D., Majumder, S., van Alphen, L. B., Savelkoul, P. H., \& Wolffs, P. F. (2016). Dissemination of antimicrobial resistance in microbial ecosystems through horizontal gene transfer. Frontiers in Microbiology, 7, 173. https://doi.org/10.3389/fmicb.2016.00173

Wassenaar, T. M. (2005). The use of antimicrobial agents in veterinary medicine and implications for human health. Critical Reviews in Microbiology, 31(3), 155-169. https://doi.org/10.1080/10408410591005110

\section{Copyrights}

Copyright for this article is retained by the author(s), with first publication rights granted to the journal.

This is an open-access article distributed under the terms and conditions of the Creative Commons Attribution license (http://creativecommons.org/licenses/by/4.0/). 